\title{
The Status of Nutritional Management Guidelines for Head and Neck Cancer Patients
}

Patricia Curtin ${ }^{1}$, Aelia Akbar ${ }^{2}$, Holly Kramer ${ }^{3}$, Aqsa Iqbal ${ }^{4}$, Talar Markossian ${ }^{5}$

1. Medicine, Loyola University Medical Center, Chicago, USA 2. Internal Medicine, Loyola University Medical Center, Chicago, USA 3. Nephrology, Loyola University Medical Center, Chicago, USA 4. Cardiology, University of Illinois at Chicago, Chicago, USA 5. Epidemiology and Public Health, Loyola University Medical Center, Chicago, USA

Corresponding author: Aelia Akbar, aeliausmle@gmail.com

\section{Abstract}

\section{Introduction}

Head and neck cancer (HNC) is the seventh leading cause of cancer worldwide. Approximately 35\%-60\% patients with HNC are malnourished from the disease onset, malnutrition being associated with worsened health outcomes among these patients. This study aimed to review and synthesize existing guidelines regarding nutritional interventions in HNC patients and assess providers' knowledge, opinions, and practice of guidelines for the nutritional management of HNC patients.

\section{Methods}

This is a multimethod study that includes a systematic review of guidelines for nutritional intervention in HNC patients and a providers' survey regarding their knowledge and opinions regarding nutrition therapy guidelines for HNC patients.

\section{Results}

Our review yielded seven guidelines. Of the seven guidelines reviewed, all were specific to cancer patients, however, only three were specific for HNC patients. Three of the guidelines recommended using a nutritional screening tool, however, only two mentioned a specific screening tool. Out of 193 surveys included in our analysis, the highest percentage of respondents were physicians (52.4\%), followed by registered nurses (33.5\%). The majority of respondent (77.5\%) worked in a hospital-based practice, while $18.8 \%$ worked in clinic-based practice. A large proportion (46.6\%) of respondents were not aware of nutritional guidelines for HNC patients; with 23.6\% not aware of any, and 23.0\% aware of their existence but not aware of their content. The majority $(81.5 \%)$ of respondents said that a more detailed guideline should be available for HNC patient with regards to nutrition.

\section{Conclusion}

Review began 10/04/2020 Review ended 10/26/2020 Published 11/03/2020

\section{() Copyright 2020}

Curtin et al. This is an open access article distributed under the terms of the Creative Commons Attribution License CC-BY 4.0., which permits unrestricted use, distribution, and reproduction in any medium, provided the original author and source are credited.
Nutritional deficiencies in HNC patients continue to cause significant complications in treatment and recovery. Existing practice guidelines are limited and lack specific recommendations. A universal standard of care with regard to addressing nutrition in HNC patients is needed to improve healthcare outcomes among NHC patients.

Categories: Internal Medicine, Otolaryngology, Oncology

Keywords: oncology, nutritional, guidelines, head and neck cancer, management

\section{Introduction}

Head and neck cancer (HNC) is the seventh leading cause of cancer worldwide [1]. It encompasses malignancies arising from mucosal surfaces of the oral cavity, pharynx, larynx, and paranasal sinuses, as well as cancers of the major and minor salivary glands [2]. According to the National Cancer Institute's (NCI's) Surveillance, Epidemiology, and End Results (SEER) more than 65,000 new cases of HNC are projected in 2020 with 14,500 deaths attributable to the disease [1]. The causative risk factors for HNC are tobacco use [3], alcohol use, and human papillomavirus (HPV) infection [2]. Studies have shown that smokers consume less fruits and vegetables than non-smokers [4], in turn, low carotenoid intake and other protective components of fruits and vegetables is associated with increased risk of HNC [5]. Approximately 35\%-60\% patients with HNC are malnourished from the disease onset [6]. In addition, tumor location and side effects of multimodal therapy further places HNC patients at increased risk of malnutrition [7,8]. During radiation therapy, 44\%$88 \%$ of HNC patients are malnourished [8-10]. Malnutrition can be defined as an unintentional weight loss of greater than $5 \%$ in three months or $10 \%$ in six months [11] or body mass index (BMI) of less than 20 $\mathrm{kg} / \mathrm{m}^{2}[11,12]$. Albumin deficiency with albumin level less than $35 \mathrm{~g} / \mathrm{L}$ in an acutely ill patient also suggests malnutrition [13-16]. Malnutrition causes decreased response to therapy, decreased immunocompetency, increased risk of infections, increased post-operative complication rates, and decreased survival rates 
$[14,17,18]$. Therefore, a delayed diagnosis of malnutrition in HNC patient may result in delayed nutritional intervention causing increased mortality in these patients. Nutritional interventions such as weight monitoring and nutritional counseling have been shown to improve health outcomes in HNC patients by decreasing weight loss, improving quality of life, and physical function [19]. It is imperative that HNC patients are screened in a timely manner for malnutrition and referred for nutrition management [20].

There are some screening methods that are available for the early diagnoses of malnutrition among HNC patients $[12,20]$. Skipper et al. reviewed eleven different screening tools [21] and Cascio et al. reviewed five different nutritional screening tools [22]. Both studies compared nutrition screening tools for reliability and validity, and found significant differences. These studies showed that there should be a simple, easy to use and universal screening tool for malnutrition which can be used as standard across healthcare. There are several guidelines available for nutritional management in this complex patient population. However, these guidelines are not consistent in terms of screening methods, timeliness of referral, or management.

This study had two main objectives; (1) to conduct a systematic review and analysis of existing guidelines regarding nutritional interventions in HNC patients and (2) to assess providers' knowledge and practice of guidelines for the nutritional management of HNC patients. A providers' survey also queried whether more comprehensive, detailed guidelines with regard to nutritional treatment in HNC patients are needed.

\section{Materials And Methods}

This is a multimethod study that includes a systematic review of guidelines for nutritional intervention in HNC patients and a providers' survey regarding their knowledge and opinions regarding nutrition therapy guidelines for HNC patients.

\section{Guidelines review and analysis}

Data Sources

A systematic review was conducted using ClinicalKey, The Cumulative Index to Nursing and Allied Health Literature (CINAHL), and the National Guideline Clearinghouse (NGC), which are clinical guideline databases. The search string [head AND neck AND cancer AND nutrition] was used. The term 'guideline' was not included, since these were all clinical guidelines databases. A similar search was also performed in PubMed by adding the term guideline, the search string included [head AND neck AND cancer AND nutrition AND guideline]. We analyzed the guidelines and included them in our review if they addressed nutritional intervention in HNC patients. Hits that were not related to HNC were excluded. Guidelines from national and international organizations were included.

Our review yielded seven guidelines. The following guidelines were found using each search database; (1) ClinicalKey: National Comprehensive Cancer Network Guidelines (NCCN), National Institute for Health and Care Excellence (NICE), and Academy of Nutrition and Dietetics (AND). (2) CINAHL: Evidence-Based Care Sheet: Squamous Cell Carcinoma: Laryngeal and Hypopharyngeal Cancer, and Evidence-Based Care Sheet: Squamous Cell Carcinoma: Nasopharyngeal Cancer. (3) NGC: Academy of Nutrition and Dietetics (AND). (4) PubMed: American Society for Parenteral and Enteral Nutrition (ASPEN), European Society for Clinical Nutrition and Metabolism (ESPEN), National Comprehensive Cancer Network (NCCN), and Academy of Nutrition and Dietetics (AND).

Data Extraction and Synthesis

We reviewed each guideline and extracted the following information: (1) If the guideline was specifically for HNC patients, (2) the target audience for the guideline (type of practitioner), (3) if it included recommendation for referral to registered dietitian, (4) what was the time frame for referral to registered dietitian, (5) If it included recommendation for a nutritional screening tool and which tool, and (6) if it includes recommendations regarding tube feeding (Table 1 ).

\begin{tabular}{|c|c|c|c|c|c|c|c|c|}
\hline Guidelines & $\begin{array}{l}\text { Are } \\
\text { guidelines } \\
\text { specific } \\
\text { for HNC } \\
\text { patients }\end{array}$ & $\begin{array}{l}\text { Number } \\
\text { of pages }\end{array}$ & $\begin{array}{l}\text { Target } \\
\text { population } \\
\text { (type of } \\
\text { practitioner) }\end{array}$ & $\begin{array}{l}\text { Recommends } \\
\text { referral to } \\
\text { registered } \\
\text { dietician }\end{array}$ & $\begin{array}{l}\text { Time frame } \\
\text { for referral } \\
\text { to } \\
\text { registered } \\
\text { dietician }\end{array}$ & $\begin{array}{l}\text { Recommends } \\
\text { a nutritional } \\
\text { screening } \\
\text { tool }\end{array}$ & $\begin{array}{l}\text { Nutritional } \\
\text { screening tool }\end{array}$ & $\begin{array}{l}\text { Gives } \\
\text { recommendations } \\
\text { regarding tube } \\
\text { feeding }\end{array}$ \\
\hline $\begin{array}{l}\text { Nutritional } \\
\text { Comprehens } \\
\text { Cancer } \\
\text { Network } \\
\text { (NCCN) } \\
\text { guidelines }\end{array}$ & & & & & & & $\begin{array}{l}\text { Use of } \\
\text { screening tool } \\
\text { is }\end{array}$ & \\
\hline
\end{tabular}




\title{
Cureus
}

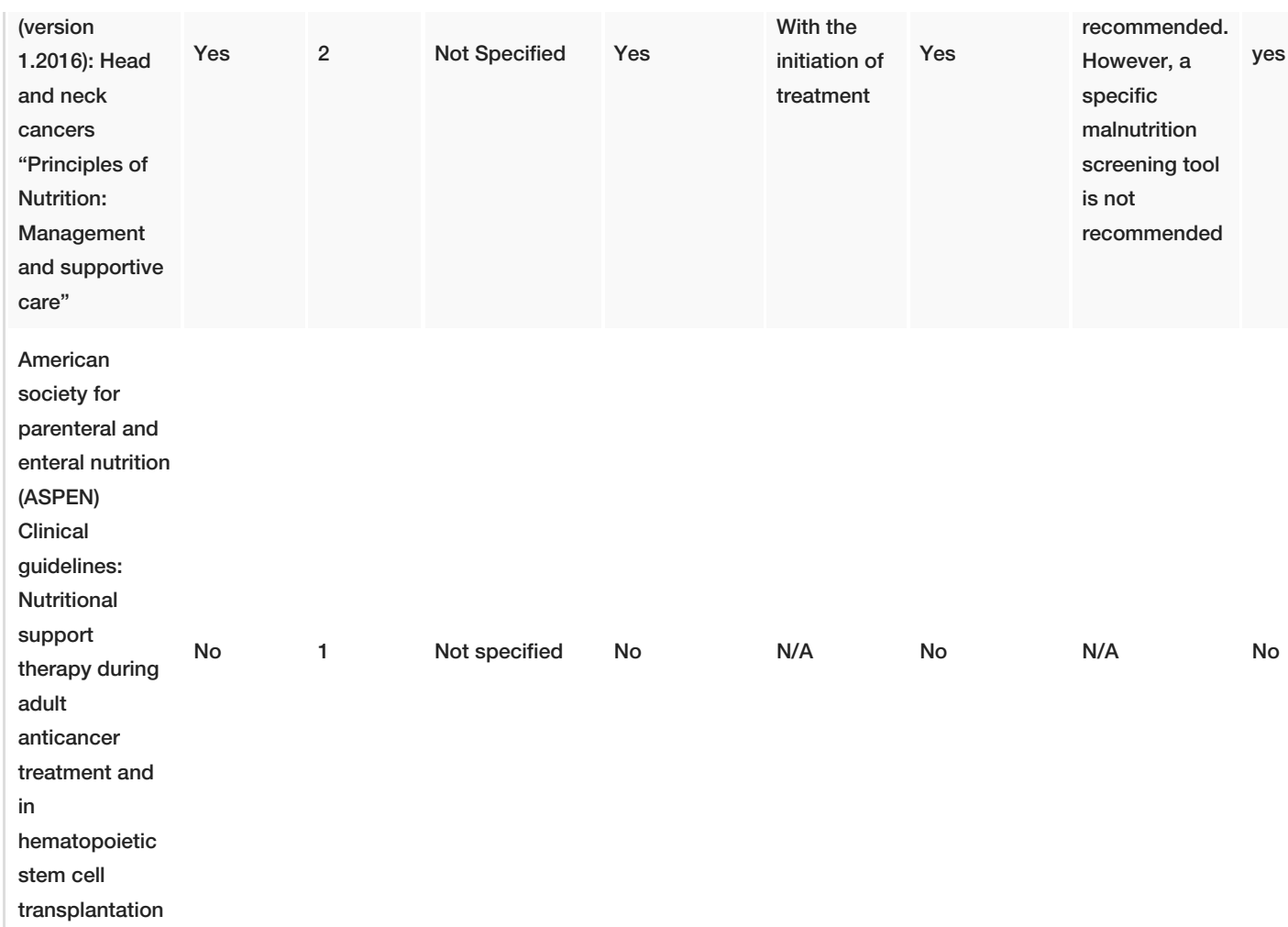

\begin{tabular}{|c|c|c|c|c|c|c|c|}
\hline $\begin{array}{l}\text { Academy of } \\
\text { nutrition and } \\
\text { dietetics (AND) } \\
\text { Oncology } 2013 \\
\text { Evidence } \\
\text { Based Nutrition } \\
\text { Practice } \\
\text { Guidelines }\end{array}$ & No & 15 & $\begin{array}{l}\text { Registered } \\
\text { Dieticians, } \\
\text { Advanced } \\
\text { Practice } \\
\text { Nurses, } \\
\text { Healthcare } \\
\text { Providers, } \\
\text { Health Plans, } \\
\text { Hospitals, } \\
\text { Managed Care } \\
\text { Organizations, } \\
\text { Nurses, } \\
\text { Physician } \\
\text { Assistants, } \\
\text { Students. }\end{array}$ & Yes & $\begin{array}{l}\text { All adults } \\
\text { patients } \\
\text { should be } \\
\text { screened } \\
\text { for } \\
\text { malnutrition } \\
\text { risk on entry } \\
\text { into } \\
\text { oncology } \\
\text { services...if } \\
\text { an adult } \\
\text { oncology } \\
\text { patient is } \\
\text { identified at } \\
\text { screening to } \\
\text { be at risk } \\
\text { for } \\
\text { malnutrition, } \\
\text { the patient } \\
\text { should be } \\
\text { referred to a } \\
\text { registered } \\
\text { dietician. }\end{array}$ & Yes & $\begin{array}{l}\text { Patient } \\
\text { Generated } \\
\text { Subjective } \\
\text { Global } \\
\text { Assessment } \\
\text { (PG_SGA). } \\
\text { Malnutrition } \\
\text { Universal } \\
\text { Screening Tool } \\
\text { (MUST). } \\
\text { Malnutrition } \\
\text { Screening Tool } \\
\text { (MST). } \\
\text { Malnutrition } \\
\text { Screening Tool } \\
\text { for Cancer } \\
\text { Patients } \\
\text { (MSTC) }\end{array}$ \\
\hline
\end{tabular}

\section{American Head}

and Neck

Society (AHNS)

AHNS are no longer available due to their age. They recommend using NCCN guidelines.

CINAHL

Nursing Journal

4 (1 line

(Evidence Yes

Based Care

regarding Nurses

nutrition)

Yes

None

No

No

Sheet)

\author{
Clinical \\ oncologists, \\ Healthcare
}




\section{Cureus}

\begin{tabular}{|c|c|c|c|c|c|c|c|c|}
\hline $\begin{array}{l}\text { The European } \\
\text { Society for } \\
\text { Clinical } \\
\text { Nutrition and } \\
\text { Metabolism } \\
\text { (ESPEN) }\end{array}$ & No & 38 & $\begin{array}{l}\text { providers } \\
\text { involved in } \\
\text { supportive care } \\
\text { of cancer } \\
\text { patients and } \\
\text { cancer } \\
\text { survivors e.g. } \\
\text { medical } \\
\text { specialists } \\
\text { involved in } \\
\text { cancer } \\
\text { treatment, } \\
\text { family } \\
\text { physicians, } \\
\text { pharmacists, } \\
\text { nurses, } \\
\text { dieticians, } \\
\text { nutritionists, } \\
\text { and exercise } \\
\text { physiologists, } \\
\text { as well as } \\
\text { medical leaders } \\
\text { and } \\
\text { administrators } \\
\text { or oncological } \\
\text { institutes. }\end{array}$ & Yes & $\begin{array}{l}\text { Not clearly } \\
\text { specified }\end{array}$ & Yes & $\begin{array}{l}\text { Use of a } \\
\text { nutrition } \\
\text { screening tool } \\
\text { is } \\
\text { recommended } \\
\text { but multiple } \\
\text { screening } \\
\text { tools are given } \\
\text { as examples: } \\
\text { MUST, MST, } \\
\text { Mini Nutritional } \\
\text { Assessment } \\
\text { Short Form } \\
\text { Revised. }\end{array}$ & Yes \\
\hline $\begin{array}{l}\text { National } \\
\text { Institute for } \\
\text { Health and } \\
\text { Care } \\
\text { Excellence } \\
\text { (NICE) (UK) }\end{array}$ & Yes & 3 & $\begin{array}{l}\text { Service } \\
\text { Providers } \\
\text { Healthcare } \\
\text { Providers } \\
\text { Commissioners. }\end{array}$ & No & N/A & No & N/A & $\begin{array}{l}\text { Recommends } \\
\text { nutritional } \\
\text { assessment at } \\
\text { diagnosis, } \\
\text { including the need } \\
\text { for tube feeding. }\end{array}$ \\
\hline
\end{tabular}

TABLE 1: Comparison of clinical guidelines for managing nutrition in head and neck cancer (HNC) patients

*All guidelines were specific to cancer patients

*None had specific guidelines for elderly patients

*None specified whether they were in-patient or out-patient care.

\section{Provider survey of nutritional interventions in HNC patients}

Target Population and Study Design

The target population consisted of healthcare providers within the United States who worked with HNC patients. A cross-sectional survey was distributed to the members of the Oncology Nursing Society (ONS) from March 5 to April 23, 2018. ONS consisted of Registered Nurses, Nurse Practitioners, Registered Dieticians and other healthcare professionals. The survey was also distributed among members of the American Head and Neck Society (AHNS) which consisted of physicians, Nurse Practitioners, Physician Assistants, and other healthcare professionals from February to December 2019. The emails of the members were directly accessed from ONS and AHNS.

The Survey Instrument

The survey instrument consisted of 32 questions. It was administered online via Survey Monkey. The questions can be found in the attached Appendix. The questions focused on three categories: providers' knowledge and practice, providers' opinions, and providers' demographics information. The first part of the survey, questions 2 to 19 collected information regarding providers' knowledge and use of practice guidelines regarding nutrition in HNC patients. The second part of the survey, from questions 20 to 26 collected providers' opinions on current guidelines and their efficacy, whether healthcare providers perceive there to be a need for a universal standard of care with regard to screening for malnutrition in HNC 
patients, and whether healthcare providers perceive there to be a need for more detailed, comprehensive treatment guidelines with regard to HNC patients. Third part of the survey, questions 27 to 32 , included questions on providers' information with regards to their age, sex, institution, and current position as a healthcare provider.

The participants were not asked to provide any identifying information, as the survey was anonymous.

\section{Study procedures}

The ONS and AHNS keep databases of email addresses of its members. An email invitation with a web link to the survey was emailed to members of the ONS and AHNS. Participants were sent one additional email several days later as a reminder. In the survey, the respondents were asked if they saw head and neck cancer patients in their practice. If the response was "Yes", they progressed to the next question. If the response was "No", a disqualification message thanked the respondent for their time. Out of the total 196 responses from ONS, 24 were automatically disqualified, and out of 141 responses from AHNS, 1 was disqualified due to the fact that the respondent did not see head and neck cancer patients in their practice. Thus, total of 312 respondents from ONS and AHNS saw head and neck patients. Out of these, 119 did not complete the questionnaire and their surveys were excluded from the analysis. In summary, we received a total of 337 surveys, we excluded if the participant did not see HNC patients $(n=25)$ and did not complete the questionnaire $(\mathrm{n}=119)$. Finally, a total of 193 surveys were included in the analysis.

\section{Ethical statement}

Solutions institutional review board (IRB) ruled that the study is exempt as the survey is anonymous.

\section{Statistical analysis}

One of the authors reviewed all the guidelines using the data extraction tool and summarized the results in a descriptive (Table 1). Two authors met weekly to review the results and address questions related to the extraction process. Results from the survey were presented in descriptive tables using univariate statistics. Participant demographics are described in Table 2 and participant responses are summarized in Tables 3-4. All analysis of survey data were conducted in Stata version 14.1. 


\section{Cureus}

\begin{tabular}{|c|c|c|c|}
\hline Characteristics & & Number & Percentage (\%) \\
\hline \multirow{6}{*}{ Type of Provider } & Registered Nurses & 64 & 33.5 \\
\hline & Nurse Practitioners & 5 & 2.6 \\
\hline & Physician Assistants & 2 & 1.0 \\
\hline & Physicians & 100 & 52.4 \\
\hline & Registered Dietitians & 3 & 1.6 \\
\hline & Other & 17 & 8.9 \\
\hline \multirow{3}{*}{ Type of Institution } & Hospital Based Practice & 148 & 77.5 \\
\hline & Clinic Based Practice & 36 & 18.8 \\
\hline & Others & 7 & 3.7 \\
\hline \multirow{2}{*}{ Gender } & Males & 78 & 41.0 \\
\hline & Females & 112 & 58.9 \\
\hline \multirow{4}{*}{ Age (years) } & 24 and younger & 3 & 1.6 \\
\hline & $25-44$ & 90 & 47.4 \\
\hline & $45-74$ & 94 & 49.5 \\
\hline & 75 and older & 3 & 1.6 \\
\hline \multirow{3}{*}{ Years in Practice } & Up to 9 years & 73 & 38.3 \\
\hline & $10-19$ & 42 & 22 \\
\hline & 20 or more & 76 & 39.8 \\
\hline \multirow{7}{*}{ Location } & Northeastern United States & 31 & 16.2 \\
\hline & Southeastern United States & 35 & 18.3 \\
\hline & Southwestern United States & 24 & 12.6 \\
\hline & Midwestern United States & 54 & 28.3 \\
\hline & Intermountain Region & 13 & 6.8 \\
\hline & Pacific Northwest Region & 12 & 6.3 \\
\hline & Outside of the United States & 22 & 11.5 \\
\hline
\end{tabular}

TABLE 2: Characteristics of the study participants who completed the survey questionnaire on Nutritional Intervention in Head and Cancer Patients ( $n=193)$

* The total number of responses may not add to 193 in all questions because of missing data in some responses.

1. Which of the following best describes your knowledge of practice guidelines regarding head and neck cancer (HNC) patients?

I am not aware of any guidelines regarding nutrition in head and neck cancer patients.

I am aware of their existence, but I am not aware of their contents. 


\section{Cureus}

I am aware of multiple practice guidelines regarding nutrition in head and neck cancer patients.

2. Does your institution have guidelines with regard to addressing nutrition in head and neck cancer patients?

Among those who answered 'yes' in question \#2 (2.a. - 2.f.) $(n=102)$

2.a. Are your institution's guidelines institution-designed, or are they adopted from the practice guidelines of a professional organization?

Institution-designed
Adopted from a professional organization

2.b. Do you know where to find your institution's guidelines with regard to addressing nutrition in head and neck cancer patients?

2.c. When was the last time you reviewed your institution's guidelines with regard to addressing nutrition in head and neck cancer patients?

Within the last week

Within the last month

Within the last year

More than a year ago

Never

2.d. Do you regularly use your institution's guidelines with regard to addressing nutrition in head and neck cancer patients?

2.e. How would you rate the effectiveness of your institution's guidelines with regards to addressing nutrition in head and neck cancer patients? (Do you feel that nutritional risks in HNC cancer patients are being addressed in a timely manner?

\begin{tabular}{|c|c|c|}
\hline Very effective & 28 & 27.7 \\
\hline Effective & 39 & 38.6 \\
\hline Adequate & 16 & 15.8 \\
\hline Could use improvement & 13 & 12.9 \\
\hline Ineffective & 1 & 0.9 \\
\hline N/A & 4 & 3.9 \\
\hline \multicolumn{3}{|c|}{$\begin{array}{l}\text { 2.f. How would you rate the thoroughness of your institution's guidelines with regard to addressing nutrition in head and } \\
\text { neck cancer patients? (Do you feel that the guidelines address all of the issues they should?) }\end{array}$} \\
\hline Very thorough & 34 & 34.0 \\
\hline Somewhat thorough & 26 & 26.0 \\
\hline Adequate & 15 & 15.0 \\
\hline Could use improvement & 15 & 15.0 \\
\hline Not thorough & 4 & 4.0 \\
\hline N/A & 6 & 6.0 \\
\hline
\end{tabular}




\section{Cureus}

3. Do you have any nutritional handouts/pamphlets that you give out to new head and neck cancer patients?

Yes

4. How helpful do you find the NCCN Guidelines regarding nutrition in head and neck cancer patients?

Very helpful

Somewhat helpful

Not very helpful

Not helpful at all

5. Do you feel that more detailed guidelines with regard to nutrition in head and neck cancer patients would improve patient care?

\section{TABLE 3: Responses to questions on provider knowledge and use of guidelines}

* The total number of responses may not add to 191 in all questions because of missing data in some responses.

${ }^{\star *}$ the total number of responses in Question $2 \mathrm{a}$ to $2 \mathrm{f}$ may not add to 101 because of missing data.

Nutritional Screening in Head and Neck Cancer Patients

Do you (personally) screen head and neck cancer patients for malnutrition?

Yes

No

Does your institution have a designated healthcare professional who screens for malnutrition in head and neck cancer patients?

Yes

If you (personally) screen for malnutrition in head and neck cancer patients, do you use a Nutrition Screening Tool? Yes

No

If you do screen for malnutrition, which screening tool do you use?

Malnutrition Screening Tool (MST)

Mini Nutrition Assessment-Short Form (MNA-SF)

Malnutrition Universal Screening Tool (MUST)

Nutritional Risk Screening 2002 (NRS)

Does your institution have a protocol in place for referring head and neck cancer patients to see a registered dietitian?

If your response to the previous question was "yes", when do you refer the patient to a registered dietitian? 


\section{Cureus}

\begin{tabular}{|c|c|c|}
\hline At or as soon after diagnosis as possible & 92 & 53.8 \\
\hline At start of treatment & 30 & 17.5 \\
\hline At a designated point during treatment & 10 & 5.8 \\
\hline Only when the patient is diagnosed with malnutrition & 23 & 13.4 \\
\hline Never & 5 & 2.9 \\
\hline Other & 11 & 6.4 \\
\hline \multicolumn{3}{|c|}{ How often are head and neck cancer patients seen by registered dietitians during treatment? } \\
\hline Never & 1 & 0.5 \\
\hline One time & 6 & 3.2 \\
\hline Weekly & 44 & 23.7 \\
\hline Monthly & 6 & 3.2 \\
\hline As Needed & 113 & 60.7 \\
\hline At another designated interval & 16 & 8.6 \\
\hline \multicolumn{3}{|c|}{ How compliant do you feel patients are with regard to seeing registered dietitians once referred? } \\
\hline Always compliant & 37 & 19.7 \\
\hline Somewhat compliant & 128 & 68.1 \\
\hline Rarely compliant & 20 & 10.6 \\
\hline Not compliant & 3 & 1.6 \\
\hline \multicolumn{3}{|c|}{$\begin{array}{l}\text { Do you think a universal standard of care with regard to screening for malnutrition in head and neck cancer patients would } \\
\text { improve healthcare outcomes? }\end{array}$} \\
\hline Yes & 177 & 93.2 \\
\hline No & 13 & 6.8 \\
\hline
\end{tabular}

TABLE 4: Responses to questions on nutritional screening in head and neck cancer patients

*The total number of responses may not add to 191 in all questions because of missing data in some responses.

\section{Results}

\section{Guideline review and analysis}

Our review yielded seven guidelines (as seen in Table 1), but one guideline (AHNS) is considered outdated and no longer available. The NCCN, CINAHL and NICE provide specific guidelines for HNC patients while ASPEN, AND, and ESPEN guidelines are not specific for HNC patients. The NCCN and ASPEN have not specified the target population but CINAHL are directed towards nurses specifically. The AND, ESPEN and NICE state the guidelines are targeted at healthcare providers which include, Registered dieticians, nurses, Physician assistants, and others. Four of the guidelines (NCCN, AND, CINAHL, ESPEN) recommend referring the HNC patients to a registered dietician. NCCN recommends referring to dietician with initiation of treatment while AND recommends screening of patients for malnutrition and then referring to dietician if they are found malnourished. Only NCCN, AND, ESPEN, recommend a nutritional screening tool but do not specify any single screening tool. The tube feeding is recommended by the NCCN, ESPEN, and NICE.

\section{Provider survey of nutritional interventions in HNC patients}

Out of 4246 invitations to member of ONS, 196 (4.6\%) responses were received, and out of 1450 invitations to AHNS, 141 (9.7\%) responses were received, with total response of 337 out of the total of 5696 invitations (5.9\%). Out of 193 surveys included in our analysis, the highest percentage of respondents were physicians (52.4\%), followed by registered nurses (33.5\%). The majority of respondent (77.5\%) worked in a hospitalbased practice, while $18.8 \%$ worked in clinic-based practice. Higher percentage of respondents were female (58.9\%). Of the 193 respondents, $1.6 \%$ were age 24 years or younger, $47.4 \%$ were between the ages of $25-44$ 
years, $49.5 \%$ were between the ages of $45-74$ years and $1.6 \%$ were age 75 years and older. While $38.3 \%$ of the respondents had been practicing for up to nine years, $22 \%$ had been practicing between 10 and 19 years, and $39.8 \%$ had been practicing 20 years or more. The scope of this study included all areas of the United States, with the largest percentage of respondents being from the Midwest (28.3\%) (Table 2).

The first part of survey was focused on providers' knowledge about nutritional guidelines in HNC patients (Table 3). A large proportion (46.6\%) of respondents were not aware of nutritional guidelines for HNC patients; with $23.6 \%$ not aware of any, and $23.0 \%$ aware of their existence but not aware of their content. Out of those who were aware of these guidelines (53.4\%); 23.6\% were aware of only their institution's guidelines, $14.1 \%$ were aware of some professional institution's guidelines, and only $15.7 \%$ were aware of multiple practice guidelines for nutrition in HNC patients. In addition, 52.8\% (102 out of 193) respondents reported that their institution had practice guidelines for nutritional management in HNC patients. Out of these 102 respondents, $44.1 \%$ reported that the guidelines were designed by their institution and $37.2 \%$ reported that they were adopted from a professional organization. Additionally, only $67 \%$ of them were aware of where to find their institution's guidelines regarding nutrition in HNC patients, with $23.8 \%$ who had never reviewed them. Out of 102 respondents who had these guidelines at their institution, $60 \%$ regularly used them to address nutrition management in HNC patients. Most (82.1\%) of the respondents noted the institution's guidelines are either effective or adequate in nutritional management of HNC patients, and 75\% noted that their institution's guidelines were either thorough or adequate. Only $13.8 \%$ either said that their institutions guidelines were not effective or needs improvement.

Approximately half of our total respondents (48.9\%) provided their HNC patients with informational handouts regarding nutrition. In addition, $44.1 \%$ of respondents found NCCN guidelines helpful. Finally, majority (81.5\%) respondents said that a more detailed guidelines should be available for HNC patient with regards to nutrition.

The second part of survey was focused on nutritional screening in HNC patients (Table 4). Most of the providers (59.7\%) personally screened their patients for malnutrition and $68.1 \%$ of total also had a designated professional who screened patients for malnutrition. Only $25.5 \%$ used a nutrition screening tool; 22\% used MST, 5\% used MNA-SF, 5\% used MUST, $12 \%$ used NRS, and the remining $56 \%$ used other tools. Majority (81.6\%) of respondents had a protocol at their institutions to refer the HNC patient to a registered dietician; with $53.8 \%$ to refer as soon as the diagnosis of HNC is made and $2.9 \%$ who don't require referring the patient to registered dietician. While $23.3 \%$ required patients to be referred to dietician at the start or sometime during treatment, $13.4 \%$ required to refer them only after a diagnosis of malnutrition was made. All of the respondents excluding one reported that patients are seen by registered dietician during treatment, and $23.7 \%$ said that they are seen weekly, while $60.7 \%$ said they are seen as needed. Majority of the respondents also answered that patients are compliant in seeing the registered dietician; $19.7 \%$ noted they are always compliant and 68.1\% noted that they are somewhat compliant. Almost all (93.2\%) of respondents noted that a universal and standard malnutrition screening tool can improve healthcare outcomes for HNC patients.

\section{Discussion}

Malnutrition in cancer patients significantly decreases response to therapy and increases the risk of complications and toxicities [23]. Malnutrition leads to impaired immune response, reduced muscle strength, increased fatigue, impaired wound healing, impaired psycho-social function, and reduced quality of life [14]. These factors can lead to increased rates of hospital admissions, readmissions, length of stay, and significant healthcare costs $[17,18]$. Furthermore, the nutritional status of head and neck cancer patients is often compromised before treatment even begins due to an altered ability to chew, swallow, or taste, resulting from the physical location of the tumors [4-10,24,25].

We found seven nutritional guidelines for cancer patients and three NCCN, CINAHL, and NICE were specific for HNC patients. Three of the guidelines recommended using a nutritional screening tool, however, only two (AND, and ESPEN) mentioned a specific screening tool. Five of the seven guidelines recommend referral of the patients to a registered dietitian, however, only two specified a time frame for referring to a dietitian. The NCCN recommends referring to dietician with the start of treatment, while AND recommend screening all cancer patients for malnutrition and referring to dietician if found to be at risk for malnutrition. There is a lack of knowledge among healthcare providers who see HNC patients regarding these guidelines and providers are often not aware of their own institution's guidelines. While there are many malnutrition screening tools available and some guidelines such as NCCN, ESPEN and AND recommend using them, majority of providers do not use them. Additionally, inconsistencies are found in timeframes for referring to registered dieticians amongst healthcare providers. Finally, majority of providers who see HNC patients recommended a detailed and universal guideline for nutritional intervention in HNC patients which can improve healthcare outcomes for HNC patients. A universal screening tool would allow non-registered dietitian healthcare professionals to screen for malnutrition at the time of diagnosis allowing for quicker interventions.

\section{Strengths and limitations}


A major strength of our study was the inclusion of healthcare providers including physicians, dieticians, nurses, and others across all regions of the United States who saw HNC patients to obtain a more generalized assessment. However, the number of providers that responded to survey was small. There is also the potential for self-selection bias, in that providers and patients with a particular interest in nutrition may have been more likely to respond to the survey, and for non-response bias. Additionally, there is the potential for social desirability bias, in that participants may have responded in a manner that they believed would be viewed favorably by the study team, although this risk may have been reduced by administering the surveys online and assuring respondents of their anonymity.

\section{Conclusions}

Nutritional deficiencies in HNC patients continue to cause significant complications in treatment and recovery. While this issue is well documented, it has not been effectively addressed. Existing practice guidelines are limited and lack specific recommendations. A universal standard of care with regard to addressing nutrition in head and neck cancer patients is needed to improve healthcare outcomes among NHC patients.

\section{Appendices}

\section{Nutrition in HNC patients questionnaire}

1. Do you treat patients with head and neck cancers?

- Yes

- No

If your answer to question 1 is yes, please continue with the survey. If your answer is no, there is no need to continue, but your time is greatly appreciated.

2. Which of the following best describes your knowledge of practice guidelines regarding nutrition in head and neck cancer (HNC) patients?

. I am not aware of any guidelines regarding nutrition in head and neck cancer patients.

. I am aware of their existence, but I am not aware of their contents.

- I am aware of only my institution's practice guidelines.

. I am aware of practice guidelines designed by a professional organization.

- I am aware of multiple practice guidelines regarding nutrition in head and neck cancer patients.

3. Does your institution have guidelines with regard to addressing nutrition in head and neck cancer patients?

- Yes

. No

4. Are your institution's guidelines institution-designed, or are they adopted from the practice guidelines of

a

· professional organization?

- Institution-designed

- Adopted from a professional organization

$\cdot \quad \mathrm{N} / \mathrm{A}$

5. If your answer to the previous question is "adopted from the practice guidelines of a professional organization", which organization's guidelines do they use?

6. Do you know where to find your institution's guidelines with regard to addressing nutrition in head and neck cancer patients? 


\section{Cureus}

$$
\begin{array}{ll}
\text {. } & \text { Yes } \\
\text {. } & \text { No } \\
\text {. } & \text { N/A }
\end{array}
$$

7. When was the last time you reviewed your institution's guidelines with regard to addressing nutrition in head and neck cancer patients?

- Within the last week

- Within the last month

. Within the last year

- More than a year ago

- Never

- N/A

8. Are you familiar with the section of the National Comprehensive Cancer Network (NCCN) Guidelines that were published at the beginning of year 2016 (Version 1.2016): Head and Neck Cancers titled "Principles of Nutrition: Management and Supportive Care"?

\footnotetext{
- Yes

- No
}

9. Are you familiar with the recent additions to the section of the NCCN Guidelines that were published at the beginning of year 2016 (Version 1.2016): Head and Neck Cancers titled "Principles of Nutrition: Management and Supportive Care" regarding alternative routes for nutrition?

$$
\begin{aligned}
& \text {. Yes } \\
& \text {. No }
\end{aligned}
$$

10. If you were to name one difference between your institution's guidelines and the NCCN guidelines, what would it be?

11. Do you regularly use your institution's guidelines with regard to addressing nutrition in head and neck cancer patients?

$$
\begin{aligned}
& \text {. } \\
& \text {. } \\
& \text { No } \\
& \text {. N/A }
\end{aligned}
$$

12. Do you (personally) screen head and neck cancer patients for malnutrition?

$$
\begin{array}{ll}
\text { - } & \text { Yes } \\
\text {. No }
\end{array}
$$

13. Does your institution have a designated healthcare professional who screens for malnutrition in head and neck cancer patients?

$$
\begin{aligned}
& \text {. } \quad \text { Yes } \\
& \text {. } \quad \text { No }
\end{aligned}
$$

14. If you (personally) screen for malnutrition in head and neck cancer patients, do you use a Nutrition Screening Tool? 


\section{Cureus}

- Yes

- No

15. If you do screen for malnutrition, which screening tool do you use?

- Malnutrition Screening Tool (MST)

- $\quad$ Mini nutrition assessment-short form (MNA-SF)

- $\quad$ Malnutrition Universal Screening Tool (MUST)

· $\quad$ Nutritional Risk Screening 2002 (NRS)

Other (please specify)

16. Does your institution have a protocol in place for referring head and neck cancer patients to see a registered dietitian?

. Yes

- No

17. If your response to the previous question was "yes", when do you refer the patient to a registered dietitian?

- At or as soon after HNC diagnosis as possible

- At start of treatment

- At a designated point during treatment

- Only when the patient is diagnosed with malnutrition

- Never

- $\quad$ Other (please specify)

18. How often are head and neck cancer patients seen by registered dietitians during treatment?

- Never

- One time

- Weekly

- Monthly

- As needed

- At another designated interval (please specify)

19. How compliant do you feel patients are with regard to seeing registered dietitians once referred?

- Always compliant

- Somewhat compliant

- Rarely compliant

- Not compliant

20. How would you rate the effectiveness of your institution's guidelines with regard to addressing nutrition 


\section{Cureus}

head and neck cancer patients? (Do you feel that nutritional risks in HNC patients are addressed in a timely manner?)

. Very effective

- Effective

- Adequate

- Could use improvement

- Ineffective

- Very ineffective

- N/A

21. How would you rate the thoroughness of your institution's guidelines with regard to addressing nutrition in head and neck cancer patients? (Do you feel that the guidelines address all of the issues they should?)

- Very thorough

- Somewhat thorough

- Adequate

- Could use improvement

. Not thorough

- N/A

22. Do you have any nutritional handouts/pamphlets that you give out to new head and neck cancer patients?

- Yes

- No

23. Do you think a universal standard of care with regard to screening for malnutrition in head and neck cancer patients would improve healthcare outcomes?

- Yes

- No

24. How helpful do you find the NCCN Guidelines regarding nutrition in head and neck cancer patients?

- Very helpful

- Somewhat helpful

- No opinion

- Not very helpful

. Not helpful at all

25. Do you have any specific recommendations for improving practice guidelines for nutrition in head and neck cancer patients? If you would like to share them, please do so below.

26. Do you feel that more detailed guidelines with regard to nutrition in head and neck cancer patients would improve patient care? 
Cureus

- Yes

No

27. Your current position:

- Certified Nursing Assistant

- Licensed Practical Nurse

- Registered Nurse

- Nurse Practitioner

Physician Assistant

Physician

Registered Dietitian

Other (please specify)

28. Type of institution:

- Hospital-based practice

- Private practice

- Health center

- Academic medical center

· Military

Other (please specify)

29. Age:

- 24 or younger

- 25-34

. $35-44$

- 45-54

- 55-64

. $65-74$

- 74 or older

30. Gender:

- Male

- Female

31. Years in practice:

. Less than 5

- 5-9 
10-14

15-19

20 or more

32. Where is your institution located?

- Northeastern United States

. Southeastern United States

- Midwestern United States

- Intermountain Region of the United States

- Pacific Northwestern United States

- Southwestern United States

- Alaska

- Hawaii

Outside of the United States/Other (please specify)

\section{Additional Information \\ Disclosures}

Human subjects: Consent was obtained by all participants in this study. Animal subjects: All authors have confirmed that this study did not involve animal subjects or tissue. Conflicts of interest: In compliance with the ICMJE uniform disclosure form, all authors declare the following: Payment/services info: All authors have declared that no financial support was received from any organization for the submitted work. Financial relationships: All authors have declared that they have no financial relationships at present or within the previous three years with any organizations that might have an interest in the submitted work. Other relationships: All authors have declared that there are no other relationships or activities that could appear to have influenced the submitted work.

\section{Acknowledgements}

We thank the American Head and Neck Society and the Oncology Nursing Society for their collaboration and assistance in providing their list to distribute our surveys.

\section{References}

1. National Cancer Institute: SEER cancer statistics review (CSR) 1975-2016 . (2020). Accessed: October 2, 2020: https://seer.cancer.gov/archive/csr/1975_2016/.

2. Cohen N, Fedewa S, Chen AY: Epidemiology and demographics of the head and neck cancer population . Oral Maxillofac Surg Clin North Am. 2018, 30:381-395. 10.1016/j.coms.2018.06.001

3. Jethwa AR, Khariwala SS: Tobacco-related carcinogenesis in head and neck cancer. Cancer Metastasis Rev. 2017, 36:411-423. 10.1007/s10555-017-9689-6

4. Birkett NJ: Intake of fruits and vegetables in smokers. Public Health Nutr. 1999, 2:217-222. $10.1017 / \mathrm{s} 1368980099000270$

5. Bradshaw PT, Siega-Riz AM, Campbell M, Weissler MC, Funkhouser WK, Olshan AF: Associations between dietary patterns and head and neck cancer: the Carolina head and neck cancer epidemiology study. Am J Epidemiol. 2012, 175:1225-1233. 10.1093/aje/kwr468

6. Alshadwi A, Nadershah M, Carlson ER, Young LS, Burke PA, Daley BJ: Nutritional considerations for head and neck cancer patients: a review of the literature. J Oral Maxillofac Surg. 2013, 71:1853-1860. 10.1016/j.joms.2013.04.028

7. Larsson M, Hedelin B, Johansson I, Athlin E: Eating problems and weight loss for patients with head and neck cancer: a chart review from diagnosis until one year after treatment. Cancer Nurs. 2005, 28:425-435. 10.1097/00002820-200511000-00004

8. Langius JAE, Doornaert P, Spreeuwenberg MD, Langendijk JA, Leemans CR, van Bokhorst-de van der Schueren MAE: Radiotherapy on the neck nodes predicts severe weight loss in patients with early stage laryngeal cancer. Radiother Oncol. 2010, 97:80-85. 10.1016/j.radonc.2010.02.017

9. Unsal D, Mentes B, Akmansu M, Uner A, Oguz M, Pak Y: Evaluation of nutritional status in cancer patients receiving radiotherapy: a prospective study. Am J Clin Oncol. 2006, 29:183-188. 10.1097/01.coc.0000198745.94757.ee

10. Gorenc M, Kozjek NR, Strojan P: Malnutrition and cachexia in patients with head and neck cancer treated 
with (chemo)radiotherapy. Reports Pract Oncol Radiother. 2015, 20:249-258. 10.1016/j.rpor.2015.03.001

11. Hickson M: Malnutrition and ageing. Postgrad Med J. 2006, 82:2-8. 10.1136/pgmj.2005.037564

12. Platek ME, Popp JV, Possinger CS, DeNysschen CA, Horvath P, Brown JK: Comparison of the prevalence of malnutrition diagnosis in head and neck, gastrointestinal, and lung cancer patients by 3 classification methods. Cancer Nurs. 2011, 34:410-416. 10.1097/NCC.0b013e318206b013

13. Higgins PA, Daly BJ, Lipson AR, Guo SE: Assessing nutritional status in chronically critically ill adult patients. Am J Crit Care. 2006, 15:166-176. 10.4037/ajcc2006.15.2.166

14. van Bokhorst-de van der Schueren MAE, van Leeuwen PAM, Sauerwein HP, Kuik DJ, Snow GB, Quak JJ: Assessment of malnutrition parameters in head and neck cancer and their relation to postoperative complications. Head Neck. 1997, 19:419-425. 10.1002/(sici)1097-0347(199708)19:5<419::aid-hed9>3.0.co;22

15. Nitenberg G, Raynard B: Nutritional support of the cancer patient: Issues and dilemmas . Crit Rev Oncol Hematol. 2000, 34:137-168. 10.1016/S1040-8428(00)00048-2

16. Langius JAE, van Dijk AM, Doornaert P, et al.: More than $10 \%$ weight loss in head and neck cancer patients during radiotherapy is independently associated with deterioration in quality of life. Nutr Cancer. 2013, 63:76-83. 10.1080/01635581.2013.741749

17. Brookes GB: Nutritional status: a prognostic indicator in head and neck cancer . Otolaryngol - Head Neck Surg. 1985, 93:69-74. 10.1177/019459988509300114

18. Ravasco P, Monteiro-Grillo I, Vidal PM, Camilo ME: Nutritional deterioration in cancer: the role of disease and diet. Clin Oncol. 2003, 15:443-450. 10.1016/S0936-6555(03)00155-9

19. Isenring EA, Capra S, Bauer JD: Nutrition intervention is beneficial in oncology outpatients receiving radiotherapy to the gastrointestinal or head and neck area. Br J Cancer. 2004, 91:447-452. 10.1038/sj.bjc.6601962

20. Kruizenga HM, Van MW, Seidell JC, Thijs A, Ader HJ, Bokhorst-de van der Schueren MAE: Effectiveness and cost-effectiveness of early screening and treatment of malnourished patients. Am J Clin Nutr. 2005, 82:1082-1089. 10.1093/ajcn/82.5.1082

21. Skipper A, Ferguson M, Thompson K, Castellanos VH, Porcari J: Nutrition screening tools: an analysis of the evidence. J Parenter Enter Nutr. 2012, 36:292-298. 10.1177/0148607111414023

22. Cascio BL, Logomarsino J V: Evaluating the effectiveness of five screening tools used to identify malnutrition risk in hospitalized elderly: a systematic review. Geriatr Nurs. 2018, 39:95-102. 10.1016/.gerinurse.2017.07.006

23. Platek ME, Johnson J, Woolf K, Makarem MS, Ompad DC: Availability of outpatient clinical nutrition services for patients with cancer undergoing treatment at comprehensive cancer centers. J Oncol Pract. 2015, 11:1-5. 10.1200/JOP.2013.001134

24. Larsson M, Hedelin B, Athlin E: Lived experiences of eating problems for patients with head and neck cancer during radiotherapy. J Clin Nurs. 2003, 12:562-570. 10.1046/j.1365-2702.2003.00751.x

25. Jager-Wittenaar H, Dijkstra PU, Vissink A, Langendijk JA, van der Laan BF, Pruim J, Roodenburg JL: Changes in nutritional status and dietary intake during and after head and neck cancer treatment. Head Neck. 2011, 33:863-870. 10.1002/hed.21546 